\title{
Socio-economic factors influencing milk donation in milk banks in India: an institutional study
}

\author{
Rajshree D. Katke*, Mohit R. Saraogi
}

Department of Obstetrics and Gynaecology, Cama \& Albless Hospital, Govt. Grant Medical College, Mumbai, Maharashtra, India

Received: 13 April 2014

Accepted: 4 May 2014

\section{*Correspondence:}

Dr. Rajshree D. Katke,

E-mail: drrajashrikatke@gmail.com

(C) 2014 Katke RD et al. This is an open-access article distributed under the terms of the Creative Commons Attribution Non-Commercial License, which permits unrestricted non-commercial use, distribution, and reproduction in any medium, provided the original work is properly cited.

\begin{abstract}
Background: Exclusive breast-feeding has irrefutably been established as the best form of nourishment for neonatal and early infantile age groups. The aim of this study was to retrospectively analyze the socio-economic factors in a developing country like India, which influence maternal motivation and willingness to donate breast milk and to make policy changes to promote the same.

Methods: Ours is a retrospective study carried out over a period of 1 year in Cama and Albless hospital in Mumbai. The 948 women donating breast milk in the year 2013, were retrospectively assessed for their socioeconomic parameters such as age, parity, family income, religion \& education. The results were further tabulated and assessed.

Results: Milk donation was least in the extremes of the reproductive age group. Parity showed an inverse relationship with milk donation. Per capita income and religion did not influence milk donation. Education showed a linear relationship with milk donation, but the milk donation even in the uneducated group of women remained significantly higher than their western counterparts.

Conclusions: Women in extremes of age in the reproductive age group and women with higher parity require more motivation to donate breast milk. In our study, milk donation is independent of per capita income and which religion a person belongs to. Milk donation can be promoted by increasing women education in India. However even uneducated women can be motivated to donated breast milk, If the importance of breast feeding is taught to the woman at a young age, \& the practice of breast feeding is inculcated into the social culture of the place.
\end{abstract}

Keywords: Milk bank, Socio-economic factors, Milk donation

\section{INTRODUCTION}

Exclusive breast-feeding has irrefutably been established as the best form of nourishment for neonatal and early infantile age groups. Breast feeding offers several advantages over top feeding - especially in developing countries with respect to being more wholesome, cheap, easily digestible, easily available, offering immune protection to the newborn \& strengthening mother-child bonding. ${ }^{1}$ The sterile nature of breast milk offers advantage over top feeding where the milk used is often contaminated and the sterilization technique used is often inadequate - especially in developing countries. Artificial feeding is an important risk factor for infant morbidity and mortality, especially in preterm births. ${ }^{2}$

Banked human milk may hence be a suitable alternative for infants whose mothers are either unable to or unwilling to provide their own breast milk. ${ }^{3}$ It is for this reason that the last two decades have seen the establishment of several milk banks across the globe (517). India itself has 10 milk banks (5 of which are in the city of Mumbai). ${ }^{4}$ These milk banks have contributed significantly to the decline in neonatal and infant mortality in the regions where they are available. 
Banked human milk is used mainly in the NICUs in many conditions such as prematurity, low birth weight babies, malabsorption syndrome, maternal illness, intractable diarrhea \& Necrotizing Enterocolitis (NEC). Banked human milk significantly reduces the risk of NEC and neonatal infections. ${ }^{5,6}$

The milk bank in Cama and Albless Hospital in Mumbai was started in the year 2008. Since then it has helped provide human milk to over 15261 needy babies fitting into the eligibility criteria.

The aim of this study was to retrospectively analyze the socio-economic factors in a developing country like India, which influence maternal motivation and willingness to donate breast milk. Such an analysis will help us identify factors that can hinder milk donation in milk banks and, if possible, implement social\& national policy changes that can change the trends for the future generations.

\section{METHODS}

Ours is a retrospective study carried out over a period of 1 year in Cama and Albless hospital in Mumbai, which is the obstetric \& gynaecological unit of a tertiary hospital (Cama hospital has its own independent functional milk bank since 2008 with an attached N.I.C.U.).

From January $1^{\text {st }} 2013$ to December $31^{\text {st }} 2013$ - 948 women donated milk at our milk bank.

The detailed socio-economic history of these women donating breast milk was retrospectively collected through our medical records for parameters such as age, parity, family income, religion \& education.

The results were tabulated for further assessment as to how the different parameters influenced milk donation \& a descriptive statistical analysis was performed.

The women who were eligible to donate milk were subject to certain inclusion criteria.

\section{Inclusion criteria}

1) Mothers willing to donate breast milk.

2) Absence of blood borne infections like HIV, hepatitis $\mathrm{B}$ and syphilis in the donor.

3) Haemoglobin of $10 \mathrm{gm} \%$ or more in the donor.

4) Absence of any serious medical or surgical disorder in the donor.

The milk was collected by hand expression or by using breast pumps in willing mothers \& was refrigerated in sterile containers for consumption within 96 hours by babies in the NICU.

\section{RESULTS}

\section{Distribution based on age}

The total number of women, who delivered at the hospital, during the study period, was 2279 . There were 16 women who delivered at home and were then admitted for post - natal care (P.N.C.).

Out of the 2295 women, the age distribution is shown in Table 1.

Table 1: Age distribution.

\begin{tabular}{|ll|}
\hline Age \\
\hline$<20$ years & $295(12.8 \%)$ \\
\hline $21-25$ years & $1216(53 \%)$ \\
\hline $26-30$ years & $508(22.1 \%)$ \\
\hline$>30$ years & $276(12 \%)$ \\
\hline
\end{tabular}

Out of the 2295 P.N.C. mothers, 948 donated breast milk in the milk bank.

Table 2: Age distribution of women donating milk.

\begin{tabular}{|ll|}
\hline Age \\
\hline$<20$ years & $99(10.4 \%)$ \\
\hline $21-25$ years & $577(60.8 \%)$ \\
\hline 26-30 years & $199(21.06 \%)$ \\
\hline$>30$ years & $73(7.7 \%)$ \\
\hline
\end{tabular}

Majority of the milk was donated by women in the age group of 21-25 years.

Table 3: Percentage of women donating breast milk in each age group.

\begin{tabular}{|ll|}
\hline Age \\
\hline$<20$ years & $33.55 \%(99 / 295)$ \\
\hline $21-25$ years & $47.45 \%(577 / 1216)$ \\
\hline $26-30$ years & $39.17 \%(199 / 508)$ \\
\hline$>30$ years & $26.44 \%(73 / 276)$ \\
\hline
\end{tabular}

Hence the milk donation rate in our set up was $41.3 \%$ of all the P.N.C mothers.

\section{Distribution based on parity}

The parity wise distribution of the 2295 women is shown in Table 4.

Table 4: Parity wise distribution of the 2295 women.

\begin{tabular}{|ll|}
\hline Parity & \\
\hline 1 & $1033(45 \%)$ \\
\hline 2 & $703(30 \%)$ \\
\hline 3 & $375(16.3 \%)$ \\
\hline$>3$ & $184(8 \%)$ \\
\hline
\end{tabular}


Table 5: Parity of women donating milk (out of 948).

\begin{tabular}{|ll|}
\hline Parity & \\
\hline 1 & $520(55 \%)$ \\
\hline 2 & $257(27 \%)$ \\
\hline 3 & $114(12 \%)$ \\
\hline$>3$ & $57(6 \%)$ \\
\hline
\end{tabular}

Table 6: Percentage of women donating breast milk in each parity group.

\begin{tabular}{|ll|}
\hline Parity & \\
\hline 1 & $50.4 \%$ \\
\hline 2 & $36.4 \%$ \\
\hline 3 & $30.4 \%$ \\
\hline$>3$ & $30 \%$ \\
\hline
\end{tabular}

\section{Distribution based on per capita income}

The distribution of the total confinements based on per capita income in INR is shown in Table 7.

Table 7: Distribution of the total confinements based on per capita income in INR.

\begin{tabular}{|ll|}
\hline Per capita income \\
\hline$<30000$ pa & $1334(58.1 \%)$ \\
\hline $30000-60000$ pa & $695(30.2 \%)$ \\
\hline $60000-90000$ pa & $184(8 \%)$ \\
\hline$>90000$ pa & $82(3.5 \%)$ \\
\hline
\end{tabular}

The distribution of women donating breast milk based on the per capita income in INR is shown in Table 8 .

Table 8: Distribution of women donating breast milk based on the per capita income in INR.

\begin{tabular}{|ll|}
\hline Per capita income \\
\hline$<30000$ pa & $62 \%(588)$ \\
\hline $30000-60000$ pa & $27 \%(256)$ \\
\hline $60000-90000$ pa & $8 \%(76)$ \\
\hline$>90000$ pa & $2.9 \%(28)$ \\
\hline
\end{tabular}

Table 9: Percentage of women donating breast milk in each per capita income group.

\begin{tabular}{|c|c|}
\hline \multicolumn{2}{|c|}{ Per capita income } \\
\hline$<30000$ pa & $44 \%$ \\
\hline $30000-60000 \mathrm{pa}$ & $36.8 \%$ \\
\hline $60000-90000 \mathrm{pa}$ & $41.3 \%$ \\
\hline$>90000$ pa & $34.1 \%$ \\
\hline
\end{tabular}

\section{Distribution based on education}

Percentage of educated women in all post natal women (2295) is shown in Table 10. Percentage of educated women in all post natal women (2295) is shown in Table 11.
Table 10: Percentage of educated women in all post natal women (2295).

\begin{tabular}{|ll|}
\hline Level of education & \\
\hline Uneducated & $33.2 \%(764)$ \\
\hline Upto primary school $\left(5^{\text {th }}\right.$ standard) & $38.3 \%(879)$ \\
\hline Upto secondary school (till $10^{\text {th }}$ standard) & $21.1 \%(486)$ \\
\hline Upto junior college (till $12^{\text {th }}$ standard) & $4.8 \%(110)$ \\
\hline Under graduation in some degree & $1.8 \%(42)$ \\
\hline Post-graduation & $0.4 \%(14)$ \\
\hline
\end{tabular}

Table 11: Percentage of women educated amidst mothers donating breast milk (948).

\section{Level of education}

Uneducated $32 \%$ (304)

Upto primary school ( $5^{\text {th }}$ standard) $\quad 36.9 \%$ (350)

Upto secondary school (till $10^{\text {th }}$ standard) $22 \%$ (208)

Upto junior college (till $12^{\text {th }}$ standard) $\quad 6 \%(57)$

Under graduation in some degree $2.2 \%(21)$

Post-graduation $0.8 \%(8)$

Table 12: Percentage of women donating breast milk in each education group.

\begin{tabular}{|ll|}
\hline Level of education & \\
\hline Uneducated & $39.7 \%$ \\
\hline Upto primary school $\left(5^{\text {th }}\right.$ standard) & $39.8 \%$ \\
\hline Upto secondary school (till $10^{\text {th }}$ standard) & $42.7 \%$ \\
\hline Upto junior college (till $12^{\text {th }}$ standard) & $51.8 \%$ \\
\hline Under graduation in some degree & $50 \%$ \\
\hline Post-graduation & $57.1 \%$ \\
\hline
\end{tabular}

\section{Distribution based on religion}

Percentage distribution based on religion is shown in Table 13.

Percentage distribution of milk donor based on religion is shown in Table 14.

Table 13: Percentage distribution based on religion.

\begin{tabular}{|ll|}
\hline Religion & \\
\hline Hindu & $1(1010) 44 \%$ \\
\hline Muslim & $1(1193) 51.9 \%$ \\
\hline Catholic & $7(47) 2 \%$ \\
\hline Others & $45(22) 0.9 \%$ \\
\hline
\end{tabular}

Table 14: Percentage distribution of milk donor based on religion.

\begin{tabular}{|ll|}
\hline Religion & \\
\hline Hindu & $414(43 \%)$ \\
\hline Muslim & $494(52.11 \%)$ \\
\hline Catholic & $30(3.1 \%)$ \\
\hline Others & $10(1 \%)$ \\
\hline
\end{tabular}


Table 15: Percentage of women in each religion donating milk.

\begin{tabular}{|ll|}
\hline Religion & \\
\hline Hindu & $40.9 \%$ \\
\hline Muslim & $41.4 \%$ \\
\hline Catholic & $63.8 \%$ \\
\hline Others & $22.2 \%$ \\
\hline
\end{tabular}

\section{DISCUSSION}

This study as was intended brings to light several interesting observations. Out of 2295 P.N.C. mothers, 948 donated breast milk in the year 2013. Hence $41.3 \%$ post natal women in our setup donated breast milk which is higher than that in most other centres. This probably reflects the widespread promotion, encouragement \& willingness of Indian women to breast feed as compared to their western counterparts.

Considering age as a parameter, the majority of milk donors belonged to the age group of 21-25 years with $60.8 \%$ donors (577 women out of 948 ) belonging to that age bracket. $47 \%$ of all post natal mothers in the age group of 21-25 (577 out of 1216 women) in our setup donated breast milk followed by $39 \%$ women in the age group of 26-30. The donation rate was $33 \%$ \& $26 \%$ respectively in the age groups $<20 \&$ more than 30 years. Hence, we can reasonably conclude that milk donation is least in the extremes of the reproductive age group. This could be due to immaturity in the age group of $<20$ years\& fatigue or sparse milk production in the age group $>30$ years, but the reasons are likely to be multifactorial.

An assessment of milk donation and parity showed an inverse relationship, with $50.4 \%$ primiparas donating milk in comparison to less than $30 \%$ donation rates in those with parity $>3$.

Per capita income showed no relationship with respect to donation of breast milk. In fact, the highest number of milk donations came from women in the group of per capita income $<30000$ pa $(44 \%)$ followed by those with per capita income $>60000-90000(41.4 \%)$ per annum. Hence willingness to donate breast milk seemed to be independent of the economic status of the patient as both rich and poor patients were found willing to donate milk. Women with per capita income >90000 had slightly lower rate of milk donation (34\%).

It is interesting to note that $39.7 \%$ of uneducated women in India agreed to donate breast milk. This figure is not far from the overall milk donation rate of $41.3 \%$ in our institute. The reason for this is probably because breast feeding is given great social importance in India. Women are taught at a very young age the importance of breast feeding, first by their parents and later by their in laws. This is why there was a high milk donation rate even in uneducated women in India.
However, milk donation showed an almost linear relationship with education, with higher donation rates in the more educated women.

When comparing women of different religion, the highest percentage of milk donors came from the Catholic community, with $63.8 \%$ of post natal catholic mothers donating breast milk. However, there were only $47(<2 \%$ of confinements) Catholic women who delivered in our set up in 2013 \& a larger sample size might be needed in order to draw any conclusion. The Hindu and Muslim community were almost equivocal in their milk donation rates with $40.9 \%$ and $41.4 \%$ of post natal Hindu and Muslim mothers respectively, donating breast milk. Only $22.2 \%$ of post natal women belonging to other communities donated breast milk.

\section{CONCLUSION}

From our study we can conclude that women in the extremes of reproductive age group and women with increasing parity have a decreased rate of donation of breast milk. While counseling patients to donate breast milk, it is empirical to focus on these groups, as they probably require further motivation and encouragement.

The role of religion in our study was inconclusive \& the family income of these women was not found to be a contributing factor to the willingness to donate breast milk.

The study of education and milk donation was interesting. It shows that local culture and social values plays a large role in influencing human behavior. Hence in a place like India, where women education still has some catching up to do with respect to its western counterparts, the milk donation rates were comparatively higher - even in the uneducated women.

With changing social trends globally, more and more women are switching to top feeding and breast feeding is becoming a dying practice. This can be prevented by incorporating breast feeding into our culture and teaching women the importance of breast feeding from a very young age. Encouraging and promoting women education will only further improve these rates.

Funding: No funding sources

Conflict of interest: None declared

Ethical approval: Not required

\section{REFERENCES}

1. Bialoskurski MA, Cox CL, Hayes J. The nature of the attachment in a neonatal intensive care unit. $\mathbf{J}$ Perinat Neonat Nurs. 1999;13(1):66-77.

2. Vohr BR et al. Persistent beneficial effects of breast milk ingested in the neonatal intensive care unit on outcomes of extremely low birth weight infants at 30 months of age. Pediatr. 2007;120(4):e953-9. 
3. WHO: Global strategy on infant and young child feeding. In: WHO, eds. 55th World Health Assembly. Geneva: WHO; 2009: 1-30.

4. Sandhya Khadse, Ashwini Hiremath. Human milk bank: where every precious drop counts. Med J Western India. 2013 Feb; 41(1):45-7.

5. Lucas A, Cole TJ. Breast milk and neonatal necrotizing enterocolitis. Lancet. 1990;336:1519-23.
6. Narayan I, Prakash K et al. Randomized controlled trial of effect of raw and holder pasteurized human milk and of formula supplements on incidence of neonatal infection. Lancet. 1984;2(8412):1111-3.

DOI: $10.5455 / 2320-1770 . i j r \operatorname{cog} 20140621$

Cite this article as: Katke RD, Saraogi MR. Socioeconomic factors influencing milk donation in milk banks in India: an institutional study. Int J Reprod Contracept Obstet Gynecol 2014;3:389-93. 